\title{
Work of a rehabilitation medicine service
}

\author{
C W Roy, Y Arthurs, J Hunter, S Parker, A McLaren
}

\begin{abstract}
The results of the work of the Edinburgh Rehabilitation Medicine Service in one year were evaluated. Over 1400 new patients were seen, of whom 525 were in hospital at the time. Patients most often referred were those who had had cardiovascular accidents, back pain, lower limb amputations, and head injuries and those convalescing after heart surgery. Most patients had several problems. Many were referred so that they could obtain wheelchairs or other appliances, or for assessment of their ability to drive. Only $3 \%$ of the referrals were considered inappropriate. Of the inpatients, $455(87 \%)$ returned home after treatment, but $13(2 \%)$ did not respond satisfactorily to rehabilitation. Twelve per cent $(18 \%$ of the inpatients) were referred from other health boards, suggesting a need for similar facilities elsewhere.
\end{abstract}

\section{Introduction}

In 1972 the Mair report recommended that rehabilitation medicine should be designated a new specialty in Scotland. ' Services in Lothian developed in response to this, the first patients being treated in 1975. Four consultants oversee the service, which includes two hospitals, a community physiotherapy clinic, and a wheelchair and driving assessment centre. A general practitioner supervises a community rehabilitation service in west Lothian. Each consultant works with a team comprising junior medical staff, nurses, occupational therapists, and physiotherapists. Social work, speech therapy, and psychology services are shared among these teams. There is a disabled living centre at one of the hospitals. Bioengineering services are available but do not form part of the rehabilitation medicine establishment. There is a close liaison with other specialties, particularly neurosurgery, orthopaedics, and cardiology, and a similar liaison is developing with urology; we also work closely with the social services and voluntary agencies. The overall pattern is similar to a "Regional Disability Unit" as described in the Royal College of Physicians' report Physical Disability in 1986 and Beyond. ${ }^{2}$

Any new service should be assessed before it is introduced all over the country but this presents difficulties. ${ }^{3}$ End points such as mortality have only limited relevance, and recording unemployment rates has lost much of its usefulness in today's economic circumstances. A unit's activity may, however, be assessed; the allocation of scores for activities of daily living, the number of patients who return home, and the complication rates give some idea of the quality of the service. We therefore undertook a study to answer the following questions: What type of patients are referred for rehabilitation? How long do they wait for, and undergo, treatment? What services do they use? Do they make progress? What impedes progress? The last two questions will be answered fully in a subsequent paper.
Patients and methods

All new patients seen in one calendar year were entered into the study. Patients still under treatment on 30 December were followed up until discharge or until 30 June the following year, when we stopped collecting data.

The group studied comprised, firstly, inpatients, day patients, and outpatients at the two hospitals, each patient being classified only once by the most intensive type of treatment received; secondly, outpatients seen by a physician at either the community physiotherapy clinic or the assessment centre; thirdly, patients from the community rehabilitation service; lastly, patients seen at other hospitals or in their own homes.

When patients were first seen demographic data were recorded and acute problems noted. A "problem" (which could be physical, psychological, or social) included anything that affected assessment. A simple question on outcome (improved, unchanged, worse, do not know, other) was included; patients seen only once were always assigned to "do not know" unless definite evidence on outcome became available. For inpatients and day patients independence in the activities of daily living was assessed (by a method adapted from that of Smith ${ }^{+}$) at entry to and discharge from the rehabilitation unit.

Forms were completed by medical staff, often after discussion with other members of the team, and were reviewed by $C R$ or YA to ensure consistency. The results were analysed with the statistical package for the social sciences (SPSS).

TABLE II-Most common reasons for referral

\begin{tabular}{lcc}
\hline & $\begin{array}{c}\text { No } \\
\text { of } \\
\text { patients }\end{array}$ & $\begin{array}{c}\text { \% (Of total } \\
\text { No of } \\
\text { patients) }\end{array}$ \\
\hline Cerebrovascular accident & 178 & $(13)$ \\
Non-inflammatory back pain & 171 & $(12)$ \\
Assessment after heart surgery & 111 & $(8)$ \\
Assessment for a wheelchair & 99 & $(7)$ \\
Soft tissue pain & 95 & $(7)$ \\
Lower limb amputation & 61 & $(4)$ \\
Degenerative joint disease & 54 & $(4)$ \\
Neck pain & 53 & $(4)$ \\
Head injury & 50 & $(4)$ \\
Assessment of ability to drive & 41 & $(3)$ \\
Multiple sclerosis & 41 & $(3)$ \\
Assessment after myocardial infarction or & 37 & $(3)$ \\
$\quad$ angina, or both & 37 & $(72)$ \\
Total No & 991 &
\end{tabular}

\section{Results}

There were 1418 new referrals during the year; data on 44 patients were insufficient and they were excluded, leaving $1374(97 \%)$ for analysis. There were 525 inpatients (38\%), 624 outpatients $(45 \%)$, and 78 day patients $(6 \%)$. Of the total, $37(3 \%)$ were seen at the community rehabilitation service and $97(7 \%)$ elsewhere. Hospital units referred half and general practitioners $45 \%$. Our responsibility is for patients in 
the Lothian districts, but $165(12 \%)$, including 93 inpatients ( $18 \%$ of all inpatients), lived outside the area.

Patients-Age distribution is shown in table I. Schoolchildren were usually referred so that they could obtain wheelchairs. Numbers of men and women were almost equal. The most common reasons

TABLE III-Psychological and social problems in patients also presenting with physical ailments

\begin{tabular}{lcc}
\hline & $\begin{array}{c}\text { No of } \\
\text { patients }\end{array}$ & $\begin{array}{c}\text { (\% Of total No of } \\
\text { patients) }\end{array}$ \\
\hline Anxiety & 163 & $(12)$ \\
Depression & 134 & $(10)$ \\
Personality difficulties & 121 & $(9)$ \\
Intellectual impairment & 85 & $(6)$ \\
Acute confusional states & 36 & $(3)$ \\
Unemployment & 261 & $(19)$ \\
Marital or family problems & 249 & $(18)$ \\
Social isolation & 192 & $(14)$ \\
Difficulty in finding suitable housing & 176 & $(13)$ \\
Financial problems & 129 & $(9)$ \\
\hline
\end{tabular}

«Some patients had more than one problem.

TABLE IV-Occupation at time of referral

\begin{tabular}{lrc}
\hline & No (\%) of patients \\
\hline Full time employment & $301(22)$ \\
Part time employment & 41 & $(3)$ \\
Unemployed & $155(11)$ \\
Off sick for 3 months or more & $63(5)$ \\
Housework & $185(13)$ \\
Students & $61(4)$ \\
Retired (age) & $360(26)$ \\
Retired (medical grounds) & $143(10)$ \\
Other & $15(1)$ \\
Not known & $50(4)$ \\
\hline Total & $1374(100)$ \\
\hline
\end{tabular}

for referral are listed in table II. Certain conditions occurred more often than listed here; thus 178 patients who had had cerebrovascular accidents were referred for management of acute strokes, but 79 were referred so that they could obtain wheelchairs or other appliances.

Most patients had more than one physical problem; the three systems most often affected were neurological $(48 \%)$, locomotor $(48 \%)$, and cardiovascular $(25 \%)$. Complications included urinary incontinence in 63 patients, faecal incontinence in 16, and pressure sores in 13. Of the 61 patients seen after lower limbs had been amputated, 21 had stumps that were not healing satisfactorily.

Psychological and social problems were reasons for referral in comparatively few patients $(41$ and 25 cases, respectively) but were present in two thirds of those presenting with physical ailments (table III).

Nine hundred and fifty four $(69 \%)$ of the patients had lived with their families before referral, but 285 $(21 \%)$ had lived alone, including $42(3 \%)$ who required assistance to remain in the community. Only $30(2 \%)$ had been in institutions. There was an excess of social classes IV and V in the population of Lothian districts. Occupations are shown in table IV. If students, persons over retirement age, and those with household duties are excluded, $301(42 \%)$ of the remainder were in full time employment, and $143(20 \%)$ had retired on medical grounds.

The numbers of physical, psychological, and social problems are shown in table V. Certain physical and psychological problems commonly occurred together -for example, $19 \%$ of patients with back pain were depressed, and 16\% suffered from anxiety. Anxiety was also recorded in $27 \%$ of those referred for rehabilitation after cardiac surgery or heart attacks.

Rehabilitation-At first assessment 36 (3\%) new referrals were judged inappropriate; this group had a

TABLE V-Numbers of physical, psychological, and social problems in 1374 patients

\begin{tabular}{|c|c|c|c|c|c|c|}
\hline \multirow{2}{*}{$\begin{array}{c}\text { No } \\
\text { of } \\
\text { problems }\end{array}$} & \multicolumn{2}{|c|}{ Physical problems } & \multicolumn{2}{|c|}{ Psychological problems } & \multicolumn{2}{|c|}{ Social problems } \\
\hline & No of patients & (\% Of total No of patients) & No of patients & (\% Of total No of patients) & No of patients & (\% Of total No of patients) \\
\hline $\begin{array}{l}\text { None } \\
1 \\
2 \\
3 \\
4 \\
5\end{array}$ & $\begin{array}{r}27 \\
543 \\
330 \\
232 \\
130 \\
112\end{array}$ & $\begin{array}{r}(2) \\
(40) \\
(24) \\
(17) \\
(10) \\
(8)\end{array}$ & $\begin{array}{r}745 \\
507 \\
110 \\
11 \\
1 \\
0\end{array}$ & $\begin{array}{l}(54) \\
(37) \\
(8) \\
(1) \\
(0 \cdot 07)\end{array}$ & $\begin{array}{r}653 \\
443 \\
184 \\
70 \\
21 \\
3\end{array}$ & $\begin{array}{l}(48) \\
(32) \\
(13) \\
(5) \\
(2) \\
(0 \cdot 2)\end{array}$ \\
\hline
\end{tabular}

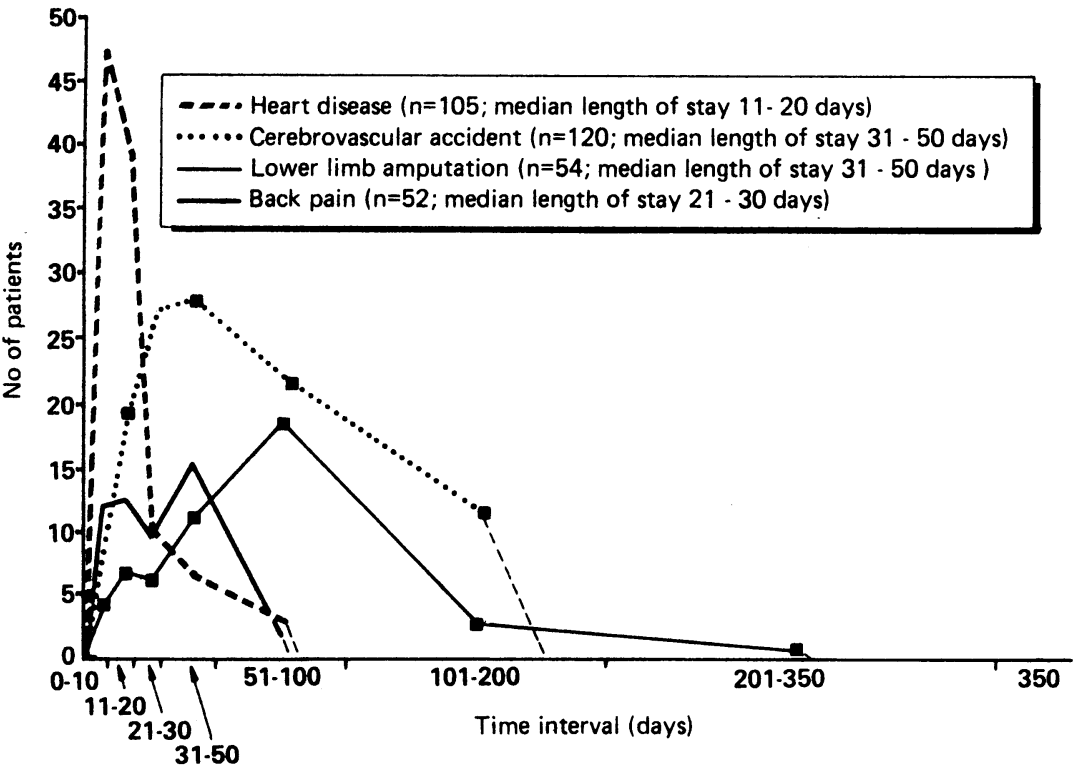

Length of stay in hospital of four diagnostic groups. Each group is represented by a single point at the middle of each time interval (horizontal axis) significantly higher percentage of patients aged over 65 $(p<0.05)$ and a larger proportion with dementia $(\mathrm{p}<0.01)$. Of the remainder, $230(17 \%)$ were seen only once and advice given; $1152(80 \%)$ were accepted for further management.

Most outpatients $(n=462,74 \%)$ were seen within a month, and $88(14 \%)$ within one week, of receipt of the request. One hundred and two patients $(16 \%)$ had longer delays for reasons beyond our control.

Many inpatient admissions were preplanned in association with elective surgery. Of the remainder, $166(51 \%)$ were admitted within a week, and $283(86 \%)$ within a month. Of the inpatients, $107(20 \%)$ were fit for discharge within 10 days and a further $132(25 \%)$ within three weeks. The median duration of stay was between three and four weeks. Twenty six patients (5\%) remained more than three months. Inpatient stay varied depending on the diagnosis: four common problems are shown in the figure. Prolonged inpatient stay was associated with difficulty in finding suitable housing $(p<0.001$, contingency coefficient test) but not with other social factors. Psychological factors did not necessarily extend admission-for example, among patients with heart diseases there was no 


\section{Discussion}

The Mair report defined rehabilitation as "restoration of the patient to their fullest physical, mental and social capacity." This unit has done what Mair envisaged. The range of diagnoses was extensive, and, except for inflammatory arthritis and chronic respiratory diseases (which are treated elsewhere in Edinburgh), was similar to that in the disabled British population in general. ${ }^{5}$ The Mair report predicted that many patients would need a "psychosociosomatic" approach; the high incidence of psychological and social problems reported here is comparable with that in previous reports about disabled people. ${ }^{67}$ Unlike Mair's expectation, however, employment rehabilitation was not a primary aim because most of our employable patients were unemployed before their current illness. Return to work is often influenced less by medical rehabilitation than by social factors. ${ }^{*}$

Many patients improved after treatment, but in evaluating a service other factors must be considered. Straightforward comparisons with other rehabilitation units are unsatisfactory, as selection criteria and illnesses treated may vary. We aimed to assess patients who might benefit from the facilities in the unit; should an individual patient fail to make sufficient progress to be discharged, he returned to his referring unit to await placement. As only $3 \%$ of referrals were judged to be inappropriate for admission we did not feel that we accepted only patients with the greatest potential for improvement.

Improvements in ability to cope with the activities of daily living occurred for most of our inpatients and outpatients, but little has been published about the changes in disability with treatment with which we may compare our figures. The proportion walking independently after strokes, however, is in accord with published figures.' The present study does not of course address the question of whether these improvements were spontaneous or the result of rehabilitation.

Lengths of stay depend in many specialties principally on diagnosis, ${ }^{10}$ but our data support the experience of others that difficulties in finding suitable housing delay discharge. This must be taken into account in comparisons of units. Early discharge may result in heavy burdens on community resources, but our results do not suggest that this happened during the study period; community services were used by fewer people after discharge than before.

We therefore consider the efficacy of our service to be acceptable, but we are concerned that even a small number of patients waited a long time for assessment. In addition, selection criteria used by our colleagues for referring patients to our unit are not clear. The high incidence of anxiety in patients with heart disease suggests that this may be a factor in their referral.

This study is to some extent an audit of our work. Donabedian" divided audit into structure, process, and outcome, but these are closely interrelated and our study comprises aspects of all three, which is necessary in any assessment of rehabilitation. Rehabilitation covers physical, psychological, and social aspects of treatment; evaluation must include each of these. Many audits in other specialties compare performance with predetermined standards. This aids analysis, but any standards in rehabilitation medicine will need to be revised as more accounts of practice in the specialty are published. Information presented here has already proved valuable in planning future developments, but the full value of auditing will only be shown if, on repeat assessment, improvements can be documented.

The current debate on the future of rehabilitation medicine indicates that the proposals of the Mair report have not been widely accepted; other Scottish 
health boards have not established broadly based units similar to our own. The Edinburgh experience may assist regional health authorities in England in planning the implementation of the recent recommendations of the Royal College of Physicians, ${ }^{2}$ but our results cannot be fully assessed until other units perform similar exercises.

1 Scottish Home and Health Department, Scottish Health Services Council Medical rehabilitation: the pattern for the future. Edinburgh: HMSO, 1972.

2 Royal College of Physicians. Physical disability in 1986 and beyond. $7 \mathrm{R} \mathrm{Coll}$ Physicians Lond 1986;20:160-94.

3 Garraway M. Stroke rehabilitation units: concepts, evaluation, and unresolved issues. Stroke 1985:16:178-81.
4 Smith ME. The Edinburgh Stroke Rehabilitation Study. $\mathrm{Br} f$ Occup Ther 1979;42:139-42.

5 Wright V. The epidemiology of disability. $f R$ Coll Physicians Lond 1982;16:178-83.

6 Jarman CMB. Living with stroke. Postgrad Med 7 1982.58.606-9.

7 Gardiner BM. Psychological aspects of rheumatoid arthritis. Psvchol Med 1980;10:159-63.

8 Cay EI, Vetter N, Philip A, Dugard P. Return to work after a heart attack. f Psychosom Res 1973;17:231-43.

9 Brudny J. New orthosis for treatment of hemiplegic shoulder subluxation Orthotics and Prosthetics 1985;39:14-20.

10 Maguire PA, Taylor IC, Stout RW. Elderly patients in acute medical wards: factors predicting length of stay in hospital. BrMed J 1986;292:1251-3.

11 Donabedian A. The quality of medical care. Science 1978;200:856-64

12 McLachlan G. Introduction and perspective. In: McLachlan G, ed. A question of quality. Oxford: Oxford University Press, 1976:3-20.

Accepted 2 Mav 1988)

\section{Hands across the equator: the Hereford/Muheza link}

\section{John B Wood, Elizabeth A Hills}

Seen from an English cathedral city, Africa is far off, exotic, and unknown, its people thought to be mostly poor and in need of basic medical care. Seen from Tanzania, England is remote and alarming, its people prosperous and healthy. We two physicians, one at Hereford County Hospital and one at Hospitali Teule, Muheza, Tanzania, have tried to bring the health workers in our communities together with two aims: that each should learn something about the other's way of life, and that some practical help should be given by the richer community to the poorer one. The idea was warmly approved by the Herefordshire Health Authority and in 1985 we began to arrange visits.

Now, in 1988, the Muheza/Hereford link is securely established, and each year four health workers from each medical community visit the other for six to eight weeks. The workers already exchanged have included nurses, doctors, engineers, pharmacists, medical assistants, a dentist, and a laboratory scientist (table).

Visitors to Hereford and Muheza

\begin{tabular}{|c|c|c|}
\hline & From Muheza & From Hereford \\
\hline Sept 1985 & Senior midwifery tutor & Community dentist \\
\hline & Senior theatre nurse & $\begin{array}{l}\text { Laboratory scientist } \\
\text { Radiographer }\end{array}$ \\
\hline May 1986 & $\begin{array}{l}\text { Senior midwife } \\
\text { Medical assistant (eves) }\end{array}$ & $\begin{array}{l}\text { Radiographer } \\
\text { Community nursing tutor }\end{array}$ \\
\hline Sept 1986 & $\begin{array}{l}\text { Senior nursing tutor } \\
\text { Psychiatric nurse }\end{array}$ & $\begin{array}{l}\text { Works officer (engineer) } \\
\text { Consultant obstetrician } \\
\text { and gynaecologist }\end{array}$ \\
\hline May 1987 & $\begin{array}{l}\text { Nurse anaesthetist } \\
\text { Medical assistant (paediatrics) }\end{array}$ & $\begin{array}{l}\text { Medical engineer } \\
\text { Ward sister(paediatrics) }\end{array}$ \\
\hline Sept 1987 & $\begin{array}{l}\text { Medical assistant (casualty) } \\
\text { Assistant medical officer (eyes and } \\
\text { general surgery) }\end{array}$ & \\
\hline Jan 1988 & Pharmacist & $\begin{array}{l}\text { Pharmacist } \\
\text { Theatre sister }\end{array}$ \\
\hline May 1988 & $\begin{array}{l}\text { Obstetrician and gynaecologist } \\
\text { Nursing officer (clinical instructor) }\end{array}$ & Staff nurse (intensive care) \\
\hline
\end{tabular}

\section{The two communities}

Muheza district, population 225000 , is in Tanga Province in north eastern Tanzania about $48 \mathrm{~km}$ County Hospital, Hereford HR1 2ER

John B Wood, FRCP, consultant physician

Hospitali Teule, Muheza, Tanga region, Tanzania Elizabeth A Hills, FRCP, medical superintendent

Correspondence to: $\mathrm{Dr}$ Wood. equator. The town lies below the Usumbara mountains, and the district is fertile, beautiful, and well watered. It has both a railway and a road that can be used in all weathers. Until 1980 Muheza district had separate small government and mission hospitals; they then amalgamated in new buildings and became the Hospitali Teule with eight wards and 200 beds. The Tanzanian government pays all the salaries in the hospital, and the mission and a charity in London provide Muheza with some extra resources. Hereford diocese supports one student nurse in the training school, and British medical students make "elective" visits.

Malaria and schistosomiasis are serious problems. Onchocerciasis is common in the mountains and filariasis on the plain. Many patients have diarrhoea and sexually transmitted diseases. Carcinoma of the oesophagus and the nephrotic syndrome are also common. Obstructed hernias often cause surgical emergencies, and there are many accidents and skin infections. The extent of human immunodeficiency virus (HIV) infection is not known, but usually there are three or four inpatients with clinically diagnosed AIDS at any time.

Muheza district, which has a larger population than Herefordshire, is served by Hospitali Teule, two rural health centres, and 26 dispensaries staffed by medical assistants and rural medical aids, as well as nurse/midwives and maternal and child health aids. Herefordshire is in the west of England on the Welsh border and has a population of 145000 . It has a district general hospital on two main sites in the city, a separate hospital for patients with mental diseases, one for eye diseases, seven small hospitals (each 24 to $36 \mathrm{~km}$ from Hereford) and a private hospital, as well as many general practitioners, and community nurses, midwives, and social workers.

\section{Travel and finance}

We have been given generous help by the Commonwealth Foundation (which has given over $£ 4000$ each year for travel expenses) and the Lennox Boyd Memorial Trust (which has given over $£ 2000$ ). The Herefordshire Health Authority has provided free accommodation for visitors and accounting and administrative help. In addition, at the start of the link there were small donations from several drug companies. The cost of the link, excluding the help provided by the health authority and the hospitality and kindness of individual people in Muheza and Hereford, has been held under $£ 6000$ for eight visits each year.

\section{Experiences}

Why do they go and what do they gain? Staff go for experience, to learn, to study a project, sometimes to teach, for the adventure of visiting a different culture, and also to return home with ideas for improvements. These extracts from reports and letters give a flavour of the experiences in Muheza of English staff.

A consultant obstetrician and gynaecologist - "Muheza 